\title{
Effects of Exopolysaccharide-Producing Cultures on the Viscoelastic Properties of Reduced-Fat Cheddar Cheese*
}

\author{
A. N. Hassan, ${ }^{1}$ S. Awad, ${ }^{1,} †$ and K. Muthukumarappan ${ }^{2}$ \\ ${ }^{1}$ Minnesota-South Dakota Dairy Foods Research Center, Dairy Science Department, and \\ ${ }^{2}$ Department of Agricultural and Biosystems Engineering, South Dakota State University, Brookings 57007
}

\begin{abstract}
The objective was to study the influence of different exopolysaccharide (EPS)-producing and nonproducing lactic cultures on the viscoelastic properties of reducedfat Cheddar cheese. Changes in the viscoelastic properties were followed over a ripening period of $6 \mathrm{mo}$. Results showed that the elastic, viscous, and complex moduli were higher in reduced-fat cheeses made with EPSnonproducing cultures than in full-fat cheese. No differences in the viscoelastic properties were found between young reduced-fat cheese made with a ropy strain of Lactococcus lactis ssp. cremoris (JFR1) and its full-fat counterpart. Interestingly, the changes in viscoelastic moduli in both full-fat cheese and reduced-fat cheese made with JFR1 during ripening followed the same pattern. Whereas the moduli increased during the first month of ripening in those 2 cheeses, a dramatic decrease was observed in all other cheeses. Slopes of the viscoelastic moduli as a function of frequency were lower in the full-fat than in reduced-fat cheeses. The creep test showed that fresh reduced-fat cheese made with JFR1 was less rigid and more deformable than that made with EPS-nonproducing cultures. The creep and recovery properties of young reduced-fat cheese made with JFR1 and the full-fat type were similar. No differences were found in the viscoelastic properties between reduced-fat cheese made with no EPS and those made with EPS-producing adjunct cultures of Streptococcus thermophilus. After 6 mo of ripening, cheeses made with EPS-producing cultures maintained lower elastic and viscous moduli than did those made with no EPS.
\end{abstract}

Received May 23, 2005.

Accepted July 15, 2005.

Corresponding author: Ashraf N. Hassan; e-mail: Ashraf.Hassan @sdstate.edu.

*Published with the approval of the director of the South Dakota Agricultural Experiment Station as Publication Number 3498 of the Journal Series. This research was supported in part by MinnesotaSouth Dakota Dairy Foods Research Center, Brookings, SD and the Midwest Dairy Association, St. Paul, MN.

$\dagger$ Current address: Department of Dairy Science and Technology, Faculty of Agriculture, Alexandria University, Egypt.
(Key words: reduced-fat cheese, Cheddar, exopolysaccharide, viscoelastic properties)

Abbreviation key: \%Crp = percentage creep recovery, EPS = exopolysaccharide, $\mathbf{F F C}=$ full-fat control cheese, $\mathbf{G}^{\prime}=$ elastic modulus, $\mathbf{G}^{\prime \prime}=$ viscous modulus, $\mathbf{G}^{*}=$ complex modulus, MNFS = moisture in nonfat substance, $\mathbf{R F C}=$ reduced-fat control cheese, $\mathbf{R F}$-JFR1 = reducedfat cheese made with the ropy culture Lactococcus lactis ssp. cremoris JFR1.

\section{INTRODUCTION}

Fat reduction is associated with many textural and flavor defects in Cheddar cheese; the texture of reducedfat Cheddar cheese is described as rubbery, dry, and grainy (Mistry, 2001). To overcome such defects, the moisture in nonfat substance (MNFS) in reduced-fat cheese is increased to a level similar to that in the full-fat type. The high levels of moisture in reduced-fat cheeses produce pasty cheese that is difficult to shred. Stabilizers such as carrageenan increase the waterbinding capacity of reduced-fat Cheddar cheese and increase the gel strength (Ma et al., 1997). However, there is often a need for using natural additives to comply with food legislation that imposes severe constraints on materials that can be used. Lactic acid bacteria are found naturally in all cheese varieties; they have "generally recognized as safe" status, and are used in making fermented dairy products. Exopolysaccharide (EPS)-producing cultures have been used in yogurt, sour cream, Mozzarella cheese, soft cheese, and whipped toppings to improve rheological properties, prevent syneresis, and replace stabilizers (Hassan et al., 1996; Perry et al., 1998; Broadbent et al., 2003; Hassan et al., 2004). Recently, EPS-producing cultures were used to produce reduced-fat Cheddar cheese with textural and melting characteristics similar to those of its full-fat counterpart (Awad et al., 2005b).

The viscoelastic properties of cheese are a function of its composition, microstructure, macrostructure, and the physicochemical state of its components (Guinee, 2002). Such properties comprise a large part of the total sensory score by cheese graders (Prentice et al., 1993). 
The objective of this work was to study the effect of different EPS-producing and nonproducing lactic cultures on the viscoelastic properties of reduced-fat Cheddar cheese.

\section{MATERIALS AND METHODS}

\section{Cultures}

An EPS-producing Streptococcus thermophilus CHCC 3534 and its EPS-negative genetic variant Streptococcus thermophilus CHCC 5842 (Chr. Hansen, Denmark), a capsule-forming nonropy Streptococcus thermophilus (Hassan et al., 1995), and a ropy Lactococcus lactic spp. cremoris (JFR1; Hassan et al., 2003) were used in this study. Culture preparation was done as previously described (Awad et al., 2005a). Commercial Cheddar starter culture (DVS 850) was obtained from Chr. Hansen (Milwaukee, WI).

\section{Cheese Making}

Raw milk was obtained from the Dairy Research and Training Facility at South Dakota State University. Cheddar cheese was manufactured from standardized ( $2 \%$ reduced fat or $3.6 \%$ full fat), pasteurized $\left(63^{\circ} \mathrm{C}\right.$ for $30 \mathrm{~min}$ and cooled to $31^{\circ} \mathrm{C}$ ) milk (100 kg) according to Awad et al. (2005a). The following 6 treatments were used: 1) FFC, full-fat control cheese made using the commercial Cheddar starter culture (DVS 850; 0.015\% $\mathrm{wt} / \mathrm{wt}$ ), 2) RFC, reduced-fat control cheese made using the commercial Cheddar starter culture (DVS 850; $0.015 \% \mathrm{wt} / \mathrm{wt}$ ), 3) RF-JFR1, reduced-fat cheese made with the ropy strain Lactococcus lactis spp. cremoris JFR1 (2\% vol/wt), 4) RF-Slab, reduced-fat cheese made with a capsule-forming nonropy Streptococcus thermophilus $(0.4 \% \mathrm{vol} / \mathrm{wt})$ plus the commercial culture (0.011\% wt/wt), 5) RF-3534, reduced-fat cheese made with EPS-producing Streptococcus thermophilus CHCC $3534(0.4 \% \mathrm{vol} / \mathrm{wt})$ plus the commercial culture $(0.011 \%$ wt/wt), and 6) RF-5842, reduced-fat cheese made with the EPS-negative genetic variant of CHCC 3534 (Streptococcus thermophilus CHCC 5842;0.4\% vol/wt) plus the commercial culture $(0.011 \% \mathrm{wt} / \mathrm{wt})$. Curd was cooked to $39^{\circ} \mathrm{C}$ and held at this temperature for $30 \mathrm{~min}$. The milling $\mathrm{pH}$ was 5.4 and salt level was $1.7 \%$.

\section{Viscoelastic Measurements}

Cheeses were sliced into thin disks $(\sim 2 \mathrm{~mm}$ thick and $28.5 \mathrm{~mm}$ in diameter) with a cheese slicer, placed into plastic bags to prevent dehydration, and stored at $20^{\circ} \mathrm{C}$ for $1 \mathrm{~h}$ before analysis. Dynamic oscillatory experiments were performed using a Viscoanalyzer (ATS Rheosystems, Rheologica Instrument Inc., Bordentown, NJ)
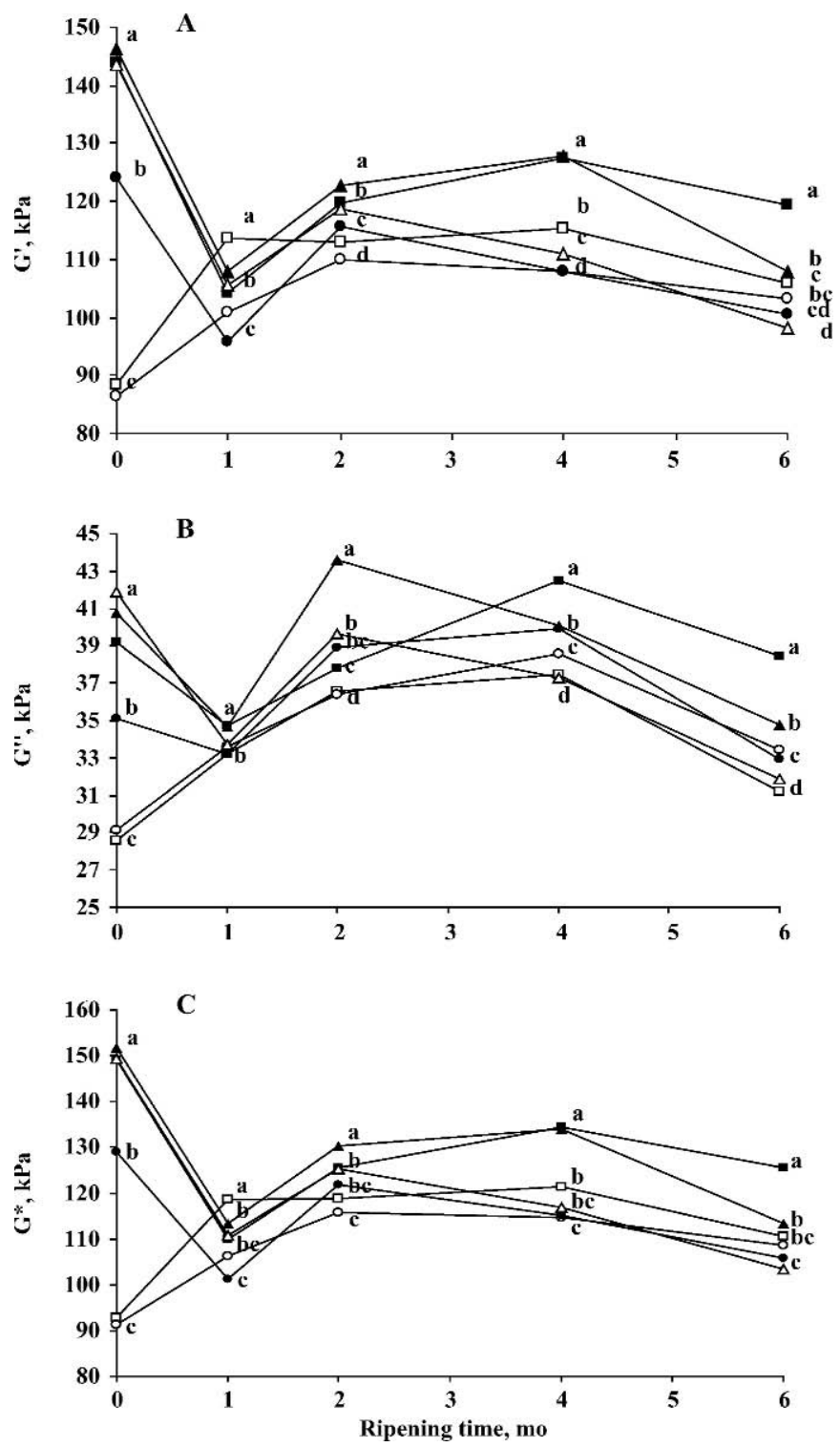

Figure 1. Changes in viscoelastic moduli during ripening of fullfat and reduced-fat Cheddar cheeses: A) Elastic modulus $\left.\left(G^{\prime}\right), B\right)$ Viscous modulus $\left(G^{\prime \prime}\right)$, and C) Complex modulus $\left(G^{*}\right) . \bigcirc=$ FFC (fullfat control), $\mathbf{\square}=$ RFC (reduced-fat control), $\square=$ RF-JFR1 (reducedfat cheese made with the ropy culture Lactococcus lactis ssp. cremoris JFR1), = RF-Slab (reduced-fat cheese made with the capsule-forming nonropy strain Streptococcus thermophilus Slab), $\Delta=\mathrm{RF}-3534$ (reduced-fat cheese made with the EPS-producing moderate ropy strain Streptococcus thermophilus CHCC 3534), and $\boldsymbol{\Delta}=$ RF-5842 (reduced-fat cheese made with the EPS-nonproducing strain Streptococcus thermophilus CHCC 5842). Different letters indicate significant differences $(P<0.05)$ within the same ripening period.

equipped with an MP parallel plate geometry (plate diameter $=30 \mathrm{~mm}$ ). The gap between the 2 plates was set to the thickness of the sample to allow good contact between the sample and the plates without deforming the cheese. Cheeses were allowed to rest for about 1 min after loading to relax stress caused by sample 
Table 1. Chemical composition (\%) and $\mathrm{pH}$ of full-fat and reduced-fat Cheddar cheeses at $\mathrm{d} 1$ of manufacture. ${ }^{1}$

\begin{tabular}{lllllll}
\hline & \multicolumn{5}{c}{ Composition $^{2}$} \\
\cline { 2 - 6 } Treatment $^{3}$ & FDM & SM & MNFS & DM & M+F & pH \\
\hline FFC & $53.22^{\mathrm{a}}$ & $3.69^{\mathrm{a}}$ & $58.50^{\mathrm{a}}$ & $60.25^{\mathrm{a}}$ & $71.8^{\mathrm{a}}$ & $5.24^{\mathrm{a}}$ \\
RFC & $35.22^{\mathrm{b}}$ & $3.35^{\mathrm{b}}$ & $53.43^{\mathrm{c}}$ & $57.35^{\mathrm{b}}$ & $62.8^{\mathrm{c}}$ & $5.26^{\mathrm{a}}$ \\
RF-JFR1 & $35.87^{\mathrm{b}}$ & $3.06^{\mathrm{c}}$ & $58.35^{\mathrm{a}}$ & $52.67^{\mathrm{c}}$ & $66.2^{\mathrm{b}}$ & $5.22^{\mathrm{a}}$ \\
RF-Slab & $35.49^{\mathrm{b}}$ & $3.27^{\mathrm{b}}$ & $54.89^{\mathrm{b}}$ & $56.01^{\mathrm{b}}$ & $63.9^{\mathrm{c}}$ & $5.21^{\mathrm{a}}$ \\
RF-3534 & $35.49^{\mathrm{b}}$ & $3.36^{\mathrm{b}}$ & $54.34^{\mathrm{bc}}$ & $56.56^{\mathrm{b}}$ & $63.5^{\mathrm{c}}$ & $5.23^{\mathrm{a}}$ \\
RF-5842 & $34.98^{\mathrm{b}}$ & $3.34^{\mathrm{b}}$ & $53.44^{\mathrm{c}}$ & $57.26^{\mathrm{b}}$ & $62.8^{\mathrm{c}}$ & $5.25^{\mathrm{a}}$ \\
\hline
\end{tabular}

a,b,c Means within a column with no common superscript differ $(P<0.05)$.

${ }^{1}$ From Awad et al. (2005a).

${ }^{2} \mathrm{FDM}=$ Fat in DM; $\mathrm{SM}=$ salt in moisture; $\mathrm{MNFS}=$ moisture in the nonfat substance; $\mathrm{M}+\mathrm{F}=$ moisture plus fat.

${ }^{3}$ Treatments: FFC = full-fat control; RFC = reduced-fat control, RF-JFR1 = reduced-fat cheese made with the ropy culture Lactococcus lactis ssp. cremoris JFR1, RF-Slab = reduced-fat cheese made with the capsuleforming nonropy strain Streptococcus thermophilus Slab, RF-3534 = reduced-fat cheese made with the moderate ropy strain Streptococcus thermophilus CHCC 3534, and RF-5842 = reduced-fat cheese made with the EPS-negative genetic variant Streptococcus thermophilus CHCC 5842.

mounting. The linear viscoelastic region of samples was determined by stress sweep measurements at $20 \pm 1^{\circ} \mathrm{C}$. The stress sweep test used logarithmic increments from 1 to $3000 \mathrm{~Pa}$ at a frequency of oscillation of $1.5 \mathrm{~Hz}$. The elastic $\left(\mathbf{G}^{\prime}\right)$, viscous $\left(\mathbf{G}^{\prime \prime}\right)$, and complex $\left(\mathbf{G}^{*}\right)$ moduli were recorded as a function of stress.

Frequency sweep measurements were carried out at a constant stress of $750 \mathrm{~Pa}$, at $20 \pm 1^{\circ} \mathrm{C}$ with increasing frequency from 0.1 to $200 \mathrm{~Hz}$. The $\mathrm{G}^{\prime}, \mathrm{G}^{\prime \prime}$, and $\mathrm{G}^{*}$ moduli were recorded as a function of frequency, and the slope of the log-log plots was calculated to determine the extent of the moduli's frequency-dependence. Stress relaxation was applied at $750 \mathrm{~Pa}$ with a strain rise of $150 \mathrm{~s}$, and a relaxation time of $150 \mathrm{~s}$. The following parameters were evaluated according to the definitions given by Brown et al. (2003): instantaneous compliance $\left(\mathrm{J}_{0}\right)$ was the compliance at time zero and was determined by extrapolation of the creep curve to time zero, maximum compliance $\left(\mathrm{J}_{\mathrm{mx}}\right)$ was the peak compliance reached by the material before the constant stress was removed, and percentage creep recovery (\%Crp) was calculated using the following relationship:

$$
\% \operatorname{Crp}=\left\{\left(\mathrm{J}_{\mathrm{mx}}-\mathrm{J}_{\mathrm{r}}\right) /\left(\mathrm{J}_{\mathrm{mx}}\right)\right\} \times 100
$$

where $J_{m x}$ is the maximum creep compliance and $J_{\mathrm{r}}$ is the compliance after recovery.

\section{Statistical Analyses}

Data reported are the average of 3 measurements per replicate. Cheeses were made 3 times for 18 cheeses total. The GLM procedure using SAS statistical analysis software package (SAS Institute, 1999) was used for ANOVA. Means separation was conducted using
Duncan's multiple range test. Differences were considered significant at $P<0.05$.

\section{RESULTS AND DISCUSSION}

The dynamic measurements were conducted in the linear viscoelastic range to keep the cheese structure intact. The linear viscoelasticity of FFC and RF-JFR1 were in the range of 0.14 to $85 \mathrm{kPa}$, and ranged from 0.12 to $160 \mathrm{kPa}$ in all other reduced-fat cheeses. The magnitude of the storage modulus $\left(G^{\prime}\right)$ was higher than that of the loss modulus $\left(G^{\prime \prime}\right)$ for all cheeses, which is typical for weak gels such as cheese and yogurt (Ma et al., 1997; Hassan et al., 2001, 2004). In agreement with previous reports (Prentice et al., 1993; Fox et al., 2000; Guinee, 2002), decreasing the fat content of cheese resulted in significant increases $(P<0.05)$ in its viscoelastic moduli (Figure 1). As casein predominates in the cheese matrix, more intra- and interstrand linkages are formed leading to greater elasticity and more resistance to deformation (Fox et al., 2000). Fat globules and MNFS act as plasticizers and soften the protein matrix (Jameson, 1990; Fox et al., 2000; Lucey et al., 2003). Results indicated that the viscoelastic moduli of cheese increased as the total filler within the network (fat plus moisture) and the MNFS decreased and the protein level increased.

Fresh RF-JFR1 had a smaller viscoelastic moduli magnitude than did all other reduced fat cheeses (Figure 1). Furthermore, there were no differences $(P>$ $0.05)$ in the storage or loss moduli between fresh FFC and RF-JFR1 cheeses. The FFC and RF-JFR1 cheeses had a similar MNFS level that was higher than that in all other reduced-fat cheeses, in which the increase in moisture resulting from fat reduction did not offset 


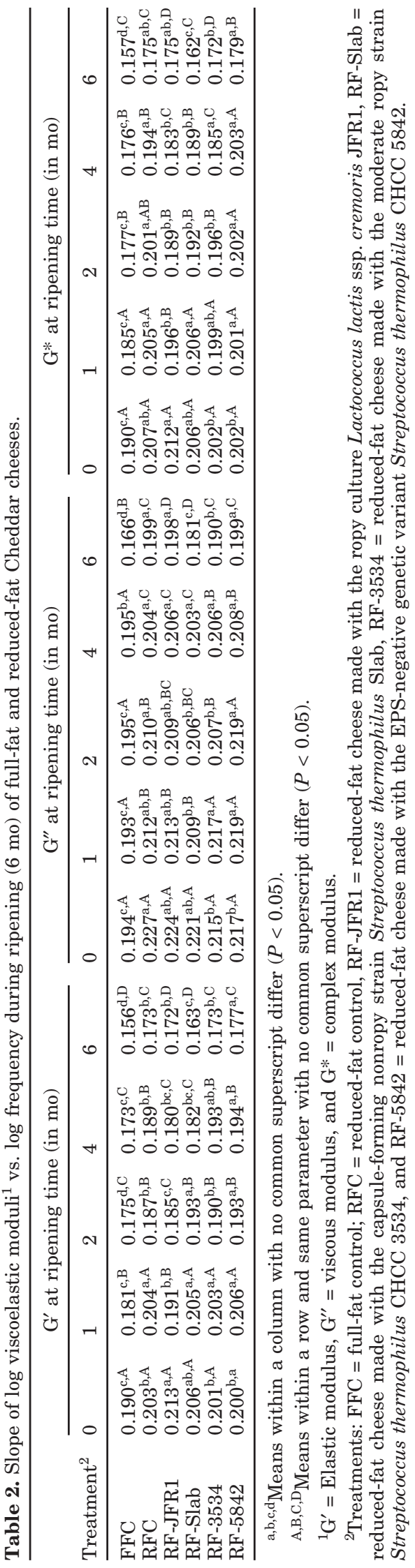

the decrease in fat (Table 1). Because the viscoelastic moduli $\left(G^{\prime}\right.$ and $G^{\prime \prime}$ ) are proportional to the number of bonds formed in the gel network (Lucey et al., 2003), it could be assumed that FFC and RF-JFR1 have less tight network structure than all other cheeses. Cryoscanning electron microscopy micrographs showed that fresh FFC contained long, wide fat serum channels (Hassan and Awad, 2005). Fresh RF-JFR1, which had the highest moisture level among all cheeses (Table 1), contained more and smaller pores than did all other reduced-fat cheeses. In addition, large pores in RFJFR1 were associated with visible EPS (Hassan and Awad, 2005). The high porosity of RF-JFR1 (due to its high moisture level and the presence of EPS) and the large fat serum channels in FFC seemed to produce a less tight network, which could lower the viscoelastic moduli of young cheeses.

After 1 mo of ripening, the viscoelastic moduli $\left(\mathrm{G}^{\prime}\right.$, $\mathrm{G}^{\prime \prime}$, and $\mathrm{G}^{*}$ ) of all cheeses except FFC and RF-JFR1 were lower $(P<0.05)$ than those in the corresponding fresh cheeses (Figure 1). It is an interesting observation that FFC and RF-JFR1 were the only treatments that showed an increase in their viscoelastic moduli during the first month of ripening. The viscoelastic data in this study correlated well with the textural and softening results reported by Awad et al. (2005b), who found that among all treatments used in the current study, FFC and RF-JFR1 had the least significant increase in their flow rate, and were the only 2 cheeses that did not show a decrease in hardness during the first month of ripening. The decrease in cheese elasticity during the early stages of ripening is due to the rapid transformation of the rubbery texture of young cheese into a smoother and softer product (Lawrence and Gilles, 1987). Such early changes in elasticity result from primary proteolysis (Lucey et al., 2003), increasing protein hydration by absorbing serum from the fat-serum channels (McMahon et al., 1999; Lucey et al., 2003), and solubilization of colloidal calcium phosphate (Lucey et al., 2003). After 1 mo of ripening, RF-JFR1 had the lowest $\mathrm{pH}$ value and highest chymosin activity among all cheeses (Awad et al., 2005a). This indicated that calcium solubilization (increases with lowering $\mathrm{pH}$ ) and primary proteolysis (increases with increasing chymosin activity) were not the main factors causing the reduction in the viscoelastic moduli during the first month of ripening. Awad et al. (2005b) suggested that early softening in texture during ripening was associated with water redistribution, which occurred less extensively in FFC and RF-JFR1 than in all other cheeses (Hassan and Awad, 2005).

The viscoelastic moduli significantly decreased $(P<$ 0.05 ) in all cheeses between mo 4 and 6 (Figure 1), which could be due to the extensive proteolysis (Lucey 
Table 3. Changes in the loss tangent $(\tan \delta$ ) during ripening of full-fat and reduced-fat Cheddar cheeses.

\begin{tabular}{llllll}
\hline & \multicolumn{5}{c}{ Ripening time (mo) } \\
\cline { 2 - 6 } Treatment $^{1}$ & 0 & 1 & 2 & 4 & 6 \\
\hline FFC & $0.32^{\mathrm{a}, \mathrm{A}}$ & $0.29^{\mathrm{b}, \mathrm{B}}$ & $0.32^{\mathrm{b}, \mathrm{A}}$ & $0.32^{\mathrm{b}, \mathrm{A}}$ & $0.29^{\mathrm{b}, \mathrm{B}}$ \\
RFC & $0.27^{\mathrm{b}, \mathrm{B}}$ & $0.33^{\mathrm{ab}, \mathrm{A}}$ & $0.32^{\mathrm{b}, \mathrm{AB}}$ & $0.33^{\mathrm{ab}, \mathrm{A}}$ & $0.32^{\mathrm{ab}, \mathrm{AB}}$ \\
RF-JFR1 & $0.33^{\mathrm{a}, \mathrm{AB}}$ & $0.33^{\mathrm{ab}, \mathrm{AB}}$ & $0.33^{\mathrm{ab}, \mathrm{AB}}$ & $0.36^{\mathrm{a}, \mathrm{A}}$ & $0.32^{\mathrm{ab}, \mathrm{B}}$ \\
RF-Slab & $0.28^{\mathrm{b}, \mathrm{D}}$ & $0.35^{\mathrm{a}, \mathrm{B}}$ & $0.34^{\mathrm{a}, \mathrm{BC}}$ & $0.36^{\mathrm{a}, \mathrm{A}}$ & $0.33^{\mathrm{a}, \mathrm{C}}$ \\
RF-3534 & $0.29^{\mathrm{b}, \mathrm{C}}$ & $0.32^{\mathrm{ab}, \mathrm{B}}$ & $0.33^{\mathrm{ab}, \mathrm{AB}}$ & $0.34^{\mathrm{ab}, \mathrm{A}}$ & $0.32^{\mathrm{ab}, \mathrm{B}}$ \\
RF-5842 & $0.28^{\mathrm{b}, \mathrm{C}}$ & $0.32^{\mathrm{ab}, \mathrm{AB}}$ & $0.34^{\mathrm{a}, \mathrm{A}}$ & $0.31^{\mathrm{b}, \mathrm{B}}$ & $0.32^{\mathrm{ab}, \mathrm{AB}}$ \\
\hline
\end{tabular}

\footnotetext{
${ }^{\mathrm{a}, \mathrm{b}}$ Means within a column with no common superscript differ $(P<0.05)$.

A,B,C,D Means within a row with no common superscript differ $(P<0.05)$.

${ }^{1}$ Treatments: $\mathrm{FFC}=$ full-fat control; RFC = reduced-fat control, RF-JFR1 = reduced-fat cheese made with the ropy culture Lactococcus lactis ssp. cremoris JFR1, RF-Slab = reduced-fat cheese made with the capsuleforming nonropy strain Streptococcus thermophilus Slab, RF-3534 = reduced-fat cheese made with the moderate ropy strain Streptococcus thermophilus CHCC 3534, and RF-5842 = reduced-fat cheese made with the EPS-negative genetic variant Streptococcus thermophilus CHCC 5842.
}

et al., 2003). Aged reduced-fat cheeses made with EPSproducing cultures were less elastic $(P<0.05)$ than were those made with no EPS. The 6-mo-old FFC and RF-JFR1 were more $(P<0.05)$ rigid than the corresponding fresh cheeses (Figure 1). However, the opposite was observed for all other cheeses. Whereas the difference in the elastic modulus between the 6-mo-old and fresh cheeses was $+17 \mathrm{kPa}$ in FFC and RF-JFR1, it ranged from -24 to $-45 \mathrm{kPa}$ in the other cheeses. This finding is consistent with the previously reported texture and softening data (Awad et al., 2005b). The extensive softening during ripening of reduced-fat cheese (which always contains high moisture levels) is not desirable as it produces pasty and difficult-to-shred cheeses. The production of EPS by RF-JFR 1 seemed to prevent extensive reduction in rigidity during ripening. The EPS produced by this strain forms a 3-D network (Hassan et al., 2003) that might entrap a significant amount of free water and prevent too much hydration of the protein during aging.

A stress of $750 \mathrm{~Pa}$ was selected for frequency sweep experiments. Viscoelastic moduli increased with increasing frequency. This trend is a general characteristic of cheese as a weak gel (Brown et al., 2003). The slopes of the viscoelastic moduli as a function of frequency were lower $(P<0.5)$ in FFC than in all reducedfat cheeses (Table 2), indicating the lower frequency dependence of the former cheese. The relatively high fat level and the presence of EPS in fresh FFC and RFJFR1, respectively, reduced G' relatively more than $G^{\prime \prime}$, which is why both cheeses were less elastic in nature than all reduced-fat cheeses, as indicated by the higher values of $\tan \delta$ (Table 3). However, FFC showed less frequency dependence than did RF-JFR1, which was similar to all other reduced-fat cheeses. This might indicate that the casein network formed in reduced-fat cheeses was different from that in FFC due to the re- duced fat level. Using cryoscanning electron microscopy, Hassan and Awad (2005) observed that reducedfat cheeses contained wider areas of protein network unoccupied with fat than did FFC. In addition, thick, solid protein strands predominated in fresh FFC, whereas a porous background protein network was observed in all reduced-fat cheeses. Such differences in cheese matrix between FFC and reduced-fat cheeses might have resulted in the variations in their frequency dependence.

Although $\tan \delta$ decreased in FFC and remained unchanged in RF-JFR1 during the first month of ripening, it significantly increased $(P<0.05)$ in all other reducedfat cheeses (Table 3). This increase in $\tan \delta$ indicated a transition to a more viscous-like behavior in the reduced-fat cheeses. The increase in $\tan \delta$ was associated with a significant increase in softening and flow rates and reduction in hardness (Awad et al., 2005b). In addition, when comparing 6-mo-old cheeses with the corresponding fresh ones, it could be seen that the 6-mo-old FFC and RF-JFR1 were the only 2 treatments that maintained the same $\tan \delta$ values. No differences in flow rates were found between the 6-mo-old FFC and RF-JFR1 and the corresponding fresh cheeses (Awad et al., 2005b). This correlation between the flow rate and $\tan \delta$ indicates the importance of the latter in the melting and flow characteristics of cheese.

Table 4 shows that all cheeses exhibited a creep response typical of viscoelastic solids. Fresh FFC and RFJFR1 had higher $(P<0.05)$ compliance values $\left(\mathrm{J}_{0}, \mathrm{~J}_{\mathrm{mx}}\right.$, and $\mathrm{J}_{\mathrm{r}}$ ) than did all other cheeses (Table 4). This indicated that fresh FFC and RF-JFR1 were less rigid, more deformable, and did not recover their initial structure as much as the other cheeses did. The viscoelastic moduli in all young cheeses were negatively correlated with $\mathrm{J}_{\mathrm{mx}}$. This finding is consistent with that reported by Brown et al. (2003). Although a significant decrease in 
viscoelastic moduli of all cheeses was found between mo 4 and 6 , the deformation was significantly reduced (lower $\mathrm{J}_{\mathrm{mx}}$ ). All viscoelastic moduli (in this study) and texture profile analysis parameters (Awad et al., 2005b) decreased in all cheeses between mo 4 and 6 except adhesiveness, which showed a sharp increase (Awad et al., 2005b). Proteolysis increases adhesiveness due to the increased ability of proteins to interact with water. This increase in adhesiveness might have decreased deformation when a constant stress was applied (lower $\mathrm{J}_{\mathrm{mx}}$ ).

The \%Crp was lower $(P<0.05)$ in fresh FFC and RFJFR1 than in all other reduced-fat cheeses (Table 5). The firmer the cheese, the smaller the deformation, and therefore, the lesser amount of strain change needed for total recovery in a given period (Drake et al., 1999; Brown et al., 2003). Fresh reduced-fat cheeses, except RF-JFR1, tended to retain more solid-like viscoelastic structure than did FFC. This finding is in agreement with those of Kuo et al. (2000) and Hassan et al. (2004). The major change in \%Crp occurred between 1 and 2 mo, during which its value significantly increased $(P<$ 0.05). Although both $\mathrm{J}_{\mathrm{mx}}$ and $\mathrm{J}_{\mathrm{r}}$ decreased during this period (Table 4), the decrease in $\mathrm{J}_{\mathrm{r}}$ (more recovery) was larger, which resulted in higher \%Crp in all cheeses. The decrease in the elasticity of cheese at the end of ripening could be related to proteolysis, as $\alpha_{\mathrm{s} 1}$-casein was completely degraded at $6 \mathrm{mo}$ of ripening in all cheeses (Awad et al., 2005a).

\section{CONCLUSIONS}

One of the major problems for manufacturers of reduced-fat Cheddar cheese is the reduction in rigidity as cheese ages. This reduction in rigidity along with the relatively high moisture levels in those cheeses makes them pasty and difficult to shred. The use of an EPSproducing culture of Lactococcus lactis ssp. cremoris prevented reduction in rigidity of reduced-fat cheese during ripening. Furthermore, changes in the viscoelastic properties of both full-fat cheese and reduced-fat cheese made with this EPS-producing culture followed the same pattern. More work is needed to study the relationship between structure of exopolysaccharides and their desirable functions in reduced-fat Cheddar cheese. This would help manufacturers select the appropriate culture to be used in making reduced-fat cheeses.

\section{ACKNOWLEDGMENTS}

This work was supported in part by the MinnesotaSouth Dakota Dairy Foods Research Center. The authors would like to thank Chr. Hansen (Milwaukee, WI) for providing starter cultures. 
Table 5. Changes in percentage creep recovery during ripening of full-fat and reduced-fat Cheddar cheeses.

\begin{tabular}{llllll}
\hline & \multicolumn{5}{c}{ Ripening time (mo) } \\
\cline { 2 - 6 } Treatment $^{1}$ & 0 & 1 & 2 & 4 & 6 \\
\hline FFC & $51.41^{\mathrm{d}, \mathrm{D}}$ & $57.48^{\mathrm{b}, \mathrm{C}}$ & $71.50^{\mathrm{ab}, \mathrm{A}}$ & $67.25^{\mathrm{c}, \mathrm{B}}$ & $61.51^{\mathrm{c}, \mathrm{C}}$ \\
RFC & $55.10^{\mathrm{b}, \mathrm{C}}$ & $58.99^{\mathrm{a}, \mathrm{B}}$ & $73.58^{\mathrm{a}, \mathrm{A}}$ & $72.72^{\mathrm{b}, \mathrm{A}}$ & $73.22^{\mathrm{ab}, \mathrm{A}}$ \\
RF-JFR1 & $51.42^{\mathrm{d}, \mathrm{C}}$ & $55.37^{\mathrm{c}, \mathrm{B}}$ & $72.86^{\mathrm{a}, \mathrm{A}}$ & $72.63^{\mathrm{b}, \mathrm{A}}$ & $72.34^{\mathrm{b}, \mathrm{A}}$ \\
RF-Slab & $57.37^{\mathrm{a}, \mathrm{D}}$ & $55.32^{\mathrm{c}, \mathrm{D}}$ & $69.97^{\mathrm{b}, \mathrm{C}}$ & $72.36^{\mathrm{b}, \mathrm{B}}$ & $75.37^{\mathrm{a}, \mathrm{A}}$ \\
RF-3534 & $52.55^{\mathrm{c}, \mathrm{C}}$ & $55.06^{\mathrm{c}, \mathrm{B}}$ & $72.16^{\mathrm{a}, \mathrm{A}}$ & $72.70^{\mathrm{b}, \mathrm{A}}$ & $72.92^{\mathrm{b}, \mathrm{A}}$ \\
RF-5842 & $58.81^{\mathrm{a}, \mathrm{C}}$ & $59.71^{\mathrm{a}, \mathrm{C}}$ & $72.41^{\mathrm{a}, \mathrm{B}}$ & $75.53^{\mathrm{a}, \mathrm{A}}$ & $74.71^{\mathrm{a}, \mathrm{A}}$ \\
\hline
\end{tabular}

a,b,c,d Means within a column with no common superscript differ $(P<0.05)$.

A,B,C,D Means within a row with no common superscript differ $(P<0.05)$.

${ }^{1}$ Treatments: FFC = full-fat control; RFC = reduced-fat control, RF-JFR1 = reduced-fat cheese made with the ropy culture Lactococcus lactis ssp. cremoris JFR1, RF-Slab = reduced-fat cheese made with the capsuleforming nonropy strain Streptococcus thermophilus Slab, RF-3534 = reduced-fat cheese made with the moderate ropy strain Streptococcus thermophilus CHCC 3534, and RF-5842 = reduced-fat cheese made with the EPS-negative genetic variant Streptococcus thermophilus CHCC 5842.

\section{REFERENCES}

Awad, S., A. N. Hassan, and F. Halaweish. 2005a. Application of exopolysaccharide-producing cultures in reduced fat Cheddar cheese: Composition and proteolysis. J. Dairy Sci. 88:4195-4203.

Awad, S., A. N. Hassan, and K. Muthukumarappan. 2005b. Application of exopolysaccharide-producing cultures in reduced fat Cheddar cheese: Texture and melting properties. J. Dairy Sci. 88:4204-4213.

Broadbent, J. R., D. J. McMahon, D. L. Welker, C. J. Oberg, and S. Moineau. 2003. Biochemistry, genetics, and applications of exopolysaccharide production Streptococcus thermophilus: A review. J. Dairy Sci. 86:407-423.

Brown, J. A., E. A. Foegeding, C. R. Daubert, M. A. Drake, and M. Gumpertz. 2003. Relationships among rheological and sensorial properties of young cheeses. J. Dairy Sci. 86:3054-3067.

Drake, M. A., P. D. Gerard, V. D. Truong, and C. R. Daubert. 1999. Relationship between instrumental and sensory measurements of cheese texture. J. Texture Stud. 30:451-476.

Fox, P. F., T. P. Guinee, T. M. Cogan, and P. L. H. McSweeney. 2000. Cheese rheology and texture. Pages 305-340 in Fundamentals of Cheese Science. Aspen Publishers, Inc., Frederick, MD.

Guinee, T. P. 2002. Cheese rheology. Pages 341-349 in Encyclopedia of Dairy Science. H. Roginski, J. W. Fuquay, and P. F. Fox, ed. Academic Press, London, UK.

Hassan, A. N., and S. Awad. 2005. Application of exopolysaccharideproducing cultures in reduced fat Cheddar cheese: Cryo-scanning electron microscopy observations. J. Dairy Sci. 88:4214-4220.

Hassan, A. N., M. Corredig, and J. F. Frank. 2001. Viscoelastic properties of yogurt made using capsule-forming nonropy lactic cultures. Milchwissenschaft 56:684-687.

Hassan, A. N., M. Corredig, J. F. Frank, and M. El-Soda. 2004. Microstructure and rheology of an acid-coagulated cheese (Karish) made with an exopolysaccharide-producing Streptococcus thermophilus strain and its exopolysaccharide non-producing genetic variant. J. Dairy Res. 71:116-120.
Hassan, A. N., J. F. Frank, and M. El-Soda. 2003. Observation of bacterial exopolysaccharide in dairy products using cryo-scanning electron microscopy. Int. Dairy J. 13:755-762.

Hassan, A. N., J. F. Frank, M. A. Farmer, K. A. Schmidt, and S. I. Shalabi. 1995. Observation of encapsulated lactic acid bacteria using confocal scanning laser microscopy. J. Dairy Sci. 78:2624-2628.

Hassan, A. N., J. F. Frank, K. A. Schmidt, and S. I. Shalabi. 1996. Textural properties of yogurt made with encapsulated nonropy lactic cultures. J. Dairy Sci. 79:2098-2103.

Jameson, M. E. 1990. Cheese with less fat. Aust. J. Dairy Technol. 11:93-98.

Kuo, M. I., Y. C. Wang, S. Gunasekaran, and N. F. Olson. 2000. Viscoelasticity index for cheese meltability evaluation. J. Dairy Sci. 83:412-417.

Lawrence, R. C., and J. Gilles. 1987. Cheddar cheese and related dry-salted cheese varieties. Pages 1-44 in Cheese: Chemistry, Physics and Microbiology. Vol. 1. P. Fox ed. Elsevier Applied Science Publishers, New York, NY.

Lucey, J. A., M. E. Johnson, and D. S. Horne. 2003. Perspectives on the basis of the rheology and texture properties of cheese. J. Dairy Sci. 86:2725-2743.

Ma, L., M. A. Drake, G. V. Barbosa-Canovas, and B. G. Swanson. 1997. Rheology of full-fat and low-fat Cheddar cheese as related to type of fat mimetic. J. Food Sci. 62:748-752.

McMahon, D. C., R. L. Fife, and C. J. Oberg. 1999. Water partitioning in Mozzarella cheese and its relationship to cheeses meltability. J. Dairy Sci. 82:1361-1369.

Mistry, V. V. 2001. Low fat cheese technology. Int. Dairy J. 11:413-422.

Perry, D. B., D. J. McMahon, and C. J. Oberg. 1998. Manufacture of low fat Mozzarella cheese using exopolysaccharide-producing starter cultures. J. Dairy Sci. 81:563-566.

Prentice, J. H., K. R. Langley, and R. J. Marshall. 1993. Cheese rheology. Pages 303-640 in Cheese: Chemistry, Physics, and Microbiology. Vol. 1. P. F. Fox ed. Chapman \& Hall, London, UK.

SAS Institute. 1999. User's Guide: Statistics, Version 8 Edition. SAS Inst., Inc., Cary, NC. 